\title{
Role of Interprofessional primary care teams in preventing avoidable hospitalizations and hospital readmissions in Ontario, Canada: a retrospective cohort study
}

Wissam Haj-Ali ${ }^{1,2,3,4^{*}}$, Rahim Moineddin ${ }^{1,2,4,5}$, Brian Hutchison ${ }^{6}$, Walter P. Wodchis ${ }^{1,2,4,7}$ and Richard H. Glazier ${ }^{1,2,4,5,8}$

\begin{abstract}
Background: Improving health system value and efficiency are considered major policy priorities internationally. Ontario has undergone a primary care reform that included introduction of interprofessional teams. The purpose of this study was to investigate the relationship between receiving care from interprofessional versus noninterprofessional primary care teams and ambulatory care sensitive condition (ACSC) hospitalizations and hospital readmissions.

Methods: Population-based administrative databases were linked to form data extractions of interest between the years of 2003-2005 and 2015-2017 in Ontario, Canada. The data sources were available through ICES. The study design was a retrospective longitudinal cohort. We used a "difference-in-differences" approach for evaluating changes in ACSC hospitalizations and hospital readmissions before and after the introduction of interprofessional team-based primary care while adjusting for physician group, physician and patient characteristics.

Results: As of March 31st, 2017, there were a total of 778 physician groups, of which 465 were blended capitation Family Health Organization (FHOs); 177 FHOs (22.8\%) were also interprofessional teams and 288 (37\%) were more conventional group practices ("non-interprofessional teams"). In this period, there were a total of 13,480 primary care physicians in Ontario of whom 4848 (36\%) were affiliated with FHOs-2311 (17.1\%) practicing in interprofessional teams and 2537 (18.8\%) practicing in non-interprofessional teams. During that same period, there were 475,611 and 618,363 multi-morbid patients in interprofessional teams and non-interprofessional teams respectively out of a total of 2,920,990 multi-morbid adult patients in Ontario. There was no difference in change over time in ACSC admissions between interprofessional and non-interprofessional teams between the pre- and post intervention periods. There were no statistically significant changes in all cause hospital readmission s between the post- and pre-intervention periods for interprofessional and non-interprofessional teams.

(Continued on next page)
\end{abstract}

\footnotetext{
* Correspondence: Wissam.haj.ali@mail.utoronto.ca

'Dalla Lana School of Public Health, Toronto, Ontario, Canada

${ }^{2}$ Institute of Health Policy, Management and Evaluation, University of

Toronto, 155 College Street, Toronto, Ontario M5T 3M6, Canada

Full list of author information is available at the end of the article
} 
(Continued from previous page)

Conclusions: Our study findings indicate that the introduction of interprofessional team-based primary care was not associated with changes in ACSC hospitalization or hospital readmissions. The findings point for the need to couple interprofessional team-based care with other enablers of a strong primary care system to improve health services utilization efficiency.

Keywords: Primary care reform, Primary health care, Avoidable hospitalizations, Health services delivery, Ontario, Canada

\section{Background}

Improving health system value and efficiency are considered major policy priorities internationally [1, 2]. While health system costs continue to be a challenge across jurisdictions, hospitalizations for ambulatory care sensitive conditions (ACSCs) and hospital readmissions have been a focus for policymakers [3-6]. ACSC hospitalizations are potentially avoidable by preventing the inception of disease, controlling an acute episodic illness, or managing a chronic condition effectively [7]. When care is delivered to patients when and where they need it, hospital readmissions can sometimes be prevented [8]. Evidence has suggested a link between the burden of multi-morbidity and health services use, particularly hospitalizations [9-12]. Hence, multi-morbid patients continue to be a key focus from a clinical care and population health perspective [13-16]. Interprofessional team-based care may have an important role to play in caring for multi-morbid patients by offering a collaborative approach to prevent ACSC hospitalization and hospital readmissions.

During the 1990s, federal and provincial governments in Canada faced fiscal challenges that resulted in limited healthcare spending and investments in primary care innovation [17]. In the 2000s, Ontario introduced primary care reform in response to the recommendations of various federal and provincial reports [18, 19]. Primary care reform movement in Ontario included three major policy initiatives: new physicians' reimbursement and organizational models, patient enrolment with a primary care provider and support to interprofessional team-based care [20]. During the last 20 years, more than one third of Ontario primary care physicians have voluntarily transitioned from traditional fee-for-service practice to blended capitation payment and in some cases received additional funding to support interprofessional team members to join their practice [21]. Ontario interprofessional Family Health Teams have many similarities with Quebec Family Medicine Groups, Alberta Primary Care Networks and the Patient-Centered Medical Home in the United States (US) [20, 22-24].

In Ontario, reducing hospitalization for ACSC conditions and all-cause readmission are strategic priorities [6, 25]. In this study, we examined the association between the introduction of primary care interprofessional teams and unplanned ACSC hospital admissions and all cause hospital readmissions among multi-morbid patients. We compared changes in those outcomes over time among physicians remunerated through the same physician payment model, some of whom transitioned to interprofessional team-based practice. We hypothesised that multi-morbid patients who receive care from an interprofessional teams will have lower ACSC hospital admissions and all-cause readmissions over time when compared to patients receiving care from noninterprofessional teams.

\section{Methods}

\section{Setting}

Ontario is the most populous province in Canada with a population of 14.4 million people in 2019 [26]. During the last two decades Ontario primary care services payment and organization have been subject to significant changes. In the early 2000s, primary care physicians were mainly paid on a fee-for-service basis and worked individually. Currently, most primary care physicians work in organised models and are largely paid through capitation. The three dominant practice models in Ontario are: enhanced fee-for-service $(85 \%$ fee-forservice, $15 \%$ capitation and bonuses, no funding for nonphysician health professionals); non-interprofessional team blended capitation (20\% fee-for-service, $80 \%$ capitation and bonuses, no funding for non-physician health professionals), and interprofessional team blended capitation (20\% fee-for-service, $80 \%$ capitation and bonuses, and funding for non-physician health professionals) [27]. The dominant model in Ontario is Family Health Organization (FHO). Within FHOs groups of physicians can be practicing in either interprofessional or noninterprofessional teams. At minimum, three physician practice together in a FHO to offer comprehensive care. FHOs were eligible to apply for additional funding to become interprofessional teams and typically include primary care physicians and nurses or nurse practitioners and at least one allied health care professional such as pharmacist, social worker or dietitian. Interprofessional teams are also eligible for funding an administrator or executive director and electronic medical records. 


\section{Study design and population}

We conducted a retrospective cohort study with longitudinal design given the importance of temporal effect on interprofessional teams formation and maturation and their relationship to the outcomes under investigation. We used the "difference in differences" approach, an econometric method for evaluating changes in outcomes after policy implementation. The difference-indifferences study design compares outcomes after and before the intervention between the study group without the exposure (group A: patients in non-interprofessional teams) and the study group with the exposure (group B: patients in interprofessional teams). Two differences in outcomes are important: the difference after vs before the implementation of interprofessional teams in the group exposed (B2 - B1) and the difference after vs before the implementation of interprofessional teams in the unexposed group (A2-A1). The change in outcomes that are related to implementation of interprofessional teams beyond background trends can then be estimated from the difference-in-differences analysis as follows: (B2-B1) - (A2-A1). If there is no relationship between implementation of interprofessional teams and subsequent outcomes, then the difference-in-differences estimate is equal to 0 . In contrast, if the implementation of interprofessional teams is associated with beneficial changes, then the outcomes following implementation will improve in the exposed group [28].

Several population-based administrative databases were linked using unique encoded identifiers at ICES (formerly known as the Institute for Clinical Evaluative Sciences) to form data extractions of interest. We generated a cohort that included the same patients at two different points in time, pre- and post-teams' formation. The study population included patients between 18 and 105 years old, who had two or more of a list of 17 chronic conditions as identified at the beginning of the pre-teams' formation period, March 31st 2003 and who were part of a FHO blended capitation model as identified at the beginning of the post-teams formation period, March 31st, 2015. The chronic condition selection was based on clinical relevance and impact on the outcomes being investigated as described in previous literature [29-34]. These conditions have been adopted in previous studies $[35,36]$ and are consistent with the parameters outlined by the Department of Health and Human Services for defining and measuring chronic conditions [37]. The conditions include: cancer, diabetes, asthma, chronic obstructive pulmonary disease (COPD), hypertension, chronic coronary syndrome (CCS), cardiac arrhythmia, congestive heart failure (CHF), stroke, acute myocardial infarction (AMI), renal failure, arthritis (excluding rheumatoid arthritis), rheumatoid arthritis, osteoporosis, depression, dementia and mental health conditions (full list of diagnostic information for defining the 17 selected chronic conditions under investigation in this study are included in Appendix 1).

The baseline study population included people identified before interprofessional teams formation who were still identifiable after interprofessional teams formation and were part of the FHO blended capitation model. People in the baseline population were followed-up to February 28th, 2005 for first unplanned ACSC admission and up to March 31st, 2005 for first all-cause readmission and in the follow up period up to February 28th, 2017 for the first ACSC admission and up to March 31st, 2017 for all-cause readmission. Given that teams did not exist during the baseline period, assignment of patients to interprofessional and non-interprofessional teams was based on their post-intervention assignment. We excluded individuals who died and individuals who were in long term care or complex continuing care.

\section{Measures and data sources ACSC admission and hospital readmission}

The primary outcome was hospital admissions for ACSCs, defined as the first hospital non-elective admission with a most responsible diagnosis code of: grand mal status and other epileptic convulsions, chronic obstructive pulmonary disease (COPD), asthma, diabetes, heart failure and pulmonary edema, hypertension and angina.

The secondary outcome was hospital readmissions, defined as the first subsequent non-elective all-cause readmission to an acute care hospital within 30 days of discharge, among hospitalisation for selected Case Mix Group (CMG) groups: stroke, COPD, pneumonia, congestive heart failure, diabetes, cardiac conditions, gastrointestinal conditions (List of CMGs codes in Appendix 2). The primary and secondary outcomes were derived from the OHIP database and the Discharge Abstract Database (DAD) and the Registered Patient Database (RPDB) available at ICES. Both outcomes excluded people without a valid date of admission/discharge; and people who died during their hospital stay (relevant to admission but not readmission).

\section{Physician group and physicians characteristics}

Physician group and physician characteristics were derived from a health care provider data registry available at ICES. Physician group characteristics included the number of physicians per group and number of years under the capitation model. Physicians' characteristics included age, sex, Canadian graduate status and number of years in practice. 


\section{Patient characteristics}

Patient characteristics were identified from a population and demographics data registry available at ICES. Patients' characteristics included age, sex and recent OHIP registration as a proxy for immigration (might include recent registrants that moved from other provinces). By linking patients' postal code to census data we were able to derive neighborhood income quintiles-quintile 1 having the lowest relative income and quintile 5 the highest. The Ontario Medical Association Rurality Index of Ontario (RIO) was used to identify rurality with a score ranging from zero (most urban) to 100 (most rural) [38].

The Resource Utilization Bands (RUBs) categories ranging from 0 (no expected utilization) to 5 (very high expected utilization) were based on the Johns Hopkins Adjusted Clinical Groups case-mix system software [39].

Six chronic diseases conditions (AMI, asthma, CHF, COPD, hypertension, diabetes) were defined based on previously validated population-derived ICES cohorts [40-45]. For the conditions where a derived ICES cohort was not available (cancer, cardiac arrhythmia, chronic coronary syndrome, dementia, depression, arthritis (excluding rheumatoid arthritis), osteoporosis, renal failure, rheumatoid arthritis, and stroke), a similar approach for the derivation was adopted-at least one diagnosis recorded in acute care, or two diagnoses recorded in physicians' records within a two-year period. The conditions were derived using the DAD and OHIP databases available at ICES.

\section{Statistical analysis}

For the descriptive results, we generated frequencies, percentages, means and standard deviations to describe the characteristics of physician groups, physicians and patients who are either in interprofessional teams or non-teams and their respective admission and readmission rates.

For the admission and readmission models, as a first step we tested for patient clustering within physicians using a random effects logistics regression. Clustering was not significant. As a result, we ran ordinary logistic regression models with binary outcomes of ACSC admission and all-cause readmission. The independent variables added to the models were the respective physician group, physician and patient characteristics.

To estimate the difference in differences we used Generalized Estimating Equations method to account for repeated measures within patients. The independent variables added to the models were the respective physician group, physician and patient characteristics.

All study analyses were conducted using SAS v.9.3 and statistical significance was assessed at a $p$-value $<0.05$.

\section{Ethics approval}

The use of data in this project was authorized under section 45 of Ontario's Personal Health Information Protection Act, which does not require review by a research ethics board.

\section{Results}

Baseline physician group, physician and patient characteristics comparing interprofessional teams to noninterprofessional teams

As of March 31st' 2017, there were a total of 778 physician groups in Ontario, of which 465 were FHOs; 177 FHOs (22.8\%) were also interprofessional teams and 288 (37\%) were non-interprofessional teams. Compared to non-interprofessional teams, interprofessional teams had: more physicians per group and more years under the capitation model.

In this period, there were a total of 13,480 primary care physicians in Ontario of whom 4848 (36\%) were affiliated with FHOs, 2311 (17.1\%) practicing in interprofessional teams and $2537(18.8 \%)$ practicing in non-interprofessional teams. Compared to noninterprofessional teams, interprofessional teams had fewer patients per physician, more female physicians, more physicians in the younger age group, more physicians who were Canadian graduates and fewer years in practice (Table 1).

During the same period, there were 475,611 and 618, 363 multi-morbid patients in interprofessional and noninterprofessional teams respectively out of a total of 2 , 920,990 multi-morbid adult patients in Ontario. Overall interprofessional teams had fewer new immigrant patients and more patients who reside in rural areas. Other patient characteristics were relatively similar between interprofessional and non-interprofessional teams. When compared to all physician groups, both interprofessional and non-interprofessional teams had less patients with high number of co-morbidities (Table 2).

\section{ACSC hospital admissions and all cause 30-day re- admissions in interprofessional teams and non- interprofessional teams by physician and patient characteristics}

During the period of April 1st, 2015 to March 31st, 2017, the unadjusted results showed that interprofessional teams were found to have higher ACSC admission rates when compared to non-interprofessional teams ( $2.5 \%$ versus $2.1 \%$, respectively). When we stratified the results by physician characteristics, the following had a higher ACSC admission rate: males, older physicians, and non-Canadian graduates (Table 3). When we stratified the results by patient characteristics, the following had a higher ACSC admission rate: males, older patients, non-immigrants, patients in the lowest neighborhood 
Table 1 Physicians group and physicians characteristics by enrolment model of care - comparing interprofessional teams to noninterprofessional teams to all groups (patient enrolment models) in Ontario based on March 31st, 2015

\begin{tabular}{|c|c|c|c|c|c|c|}
\hline \multirow{2}{*}{ Physicians' Group characteristics } & \multicolumn{2}{|c|}{ Interprofessional Teams } & \multicolumn{2}{|c|}{ Non-interprofessional teams } & \multicolumn{2}{|c|}{$\begin{array}{l}\text { All Ontario physician groups } \\
\text { (patient enrolment models) } \\
\text { and physicians }\end{array}$} \\
\hline & & & & & & \\
\hline Groups No. (\% of all PEMs) & 177 & 22.8 & 288 & 37.0 & 778 & 100.0 \\
\hline Number of physicians per group, Mean (SD) & 13.11 & 10.7 & 8.8 & 7.6 & 17 & 188.9 \\
\hline Years under the capitation model, Mean (SD) & 6.00 & 3.0 & 4.3 & 2.6 & 6 & 3.3 \\
\hline \multicolumn{7}{|l|}{ Physicians characteristics } \\
\hline Physicians No. (\% of all physicians) & 2311 & 17.1 & 2537 & 18.8 & 13,480 & 100.0 \\
\hline Number of patients per physician, Mean (SD) & 1303 & 638.9 & 1517 & 675.9 & 1020 & 944.6 \\
\hline \multicolumn{7}{|l|}{ Sex No. (\%) } \\
\hline Male & 1212 & 52.4 & 1391 & 54.8 & 7270 & 53.9 \\
\hline Female & 1099 & 47.6 & 1146 & 45.2 & 5864 & 43.5 \\
\hline Missing & 0 & 0.0 & 0 & 0.0 & 346 & 2.6 \\
\hline \multicolumn{7}{|l|}{ Age group No. (\%) in Yrs. } \\
\hline$<40$ & 546 & 23.6 & 364 & 14.4 & 2518 & 18.7 \\
\hline $40-64$ & 1499 & 64.9 & 1773 & 69.9 & 7930 & 58.8 \\
\hline$>64$ & 232 & 10.0 & 373 & 14.7 & 2031 & 15.1 \\
\hline Missing & 34 & 1.5 & 27 & 1.1 & 1001 & 7.4 \\
\hline \multicolumn{7}{|l|}{ Country of medical graduation Canada No. (\%) } \\
\hline Yes & 1874 & 81.1 & 1871 & 73.8 & 8974 & 66.6 \\
\hline No & 403 & 17.4 & 639 & 25.2 & 3505 & 26.0 \\
\hline Missing & 34 & 1.5 & 27 & 1.1 & 1001 & 7.4 \\
\hline \multicolumn{7}{|l|}{ Years in practice No. (\%) } \\
\hline$<5$ & 60 & 2.6 & 48 & 1.9 & 667 & 5.0 \\
\hline 5_15 & 701 & 30.3 & 465 & 18.3 & 3145 & 23.3 \\
\hline $16-25$ & 531 & 23.0 & 645 & 25.4 & 3047 & 22.6 \\
\hline$>25$ & 1019 & 44.1 & 1379 & 54.4 & 6275 & 46.6 \\
\hline Missing & 0 & 0.0 & 0 & 0.0 & 346 & 2.6 \\
\hline
\end{tabular}

income quintile, residents of a rural area, patients in the highest expected resource utilization band and patients with five and plus co-morbidities (Table 4).

During that same period, the unadjusted results showed that interprofessional teams had a slightly higher all cause hospital 30-day re-admission rate when compared to noninterprofessional teams (15.0\% versus 14.6\%, respectively). When we stratified the results by physician characteristics, we found that non-Canadian graduates had a higher readmission rate (Table 5). When we stratified the results by patient characteristics, the following had a higher readmission rate: males, patients in the older age category, residents of major urban areas, patients in the highest expected resource utilization band and patients with five or more co-morbidities (Table 6).

When we stratified the results by males and females for both outcomes, we did not identify sex differences (results not presented but can be made available on request).
Association between enrolment in an interprofessional team model and ACSC hospital admission and all cause hospital readmission

During the post-intervention period, when we adjusted for physician group, physician and patient characteristics, being in an interprofessional team increased the likelihood of having ACSC hospital admission by 7\%. For the same period, we did not find significant difference between interprofessional and non-interprofessional teams for hospital all cause readmission (Table 7).

When we examined difference in ACSC hospital admission during the after and before periods the difference was the $1.34 \%$ among both interprofessional teams (B2-B1) and non-interprofessional teams (A2-A1). Hence, there was no difference-in-differences (B2 - B1) - (A2 - A1).

When we examined difference in hospital readmission during the after and before periods the difference was $4.90 \%$ ( $p$-value 0.0003 ) among interprofessional teams 
Table 2 Patients' characteristics comparing patients in interprofessional teams, non-interprofessional teams, all multi-morbid patients and all Ontarians adults on March 31st, 2003

\begin{tabular}{|c|c|c|c|c|c|c|c|c|}
\hline \multirow[b]{2}{*}{ Patients total } & \multicolumn{2}{|c|}{$\begin{array}{l}\text { Multi-morbid patients in } \\
\text { interprofessional teams }\end{array}$} & \multicolumn{2}{|c|}{$\begin{array}{l}\text { Multi-morbid patients in } \\
\text { Non- interprofessional } \\
\text { teams }\end{array}$} & \multicolumn{2}{|c|}{$\begin{array}{l}\text { All multi-morbid pa- } \\
\text { tients in Ontario }\end{array}$} & \multicolumn{2}{|c|}{ All Ontarians } \\
\hline & \multicolumn{2}{|l|}{475,611} & \multicolumn{2}{|l|}{618,363} & \multicolumn{2}{|l|}{$2,920,990$} & \multicolumn{2}{|l|}{$9,397,586$} \\
\hline \multicolumn{9}{|l|}{ Sex No. (\%) } \\
\hline Males & 186,729 & 39.3 & 246,882 & 39.9 & $1,240,516$ & 42.5 & $4,576,936$ & 48.7 \\
\hline Female & 288,882 & 60.7 & 371,481 & 60.1 & $1,680,474$ & 57.5 & $4,820,650$ & 51.3 \\
\hline Missing & - & 0.0 & - & 0.0 & - & 0.0 & - & 0.0 \\
\hline \multicolumn{9}{|l|}{ Age group, yr. No. (\%) } \\
\hline $18-44$ & 138,965 & 29.2 & 184,059 & 29.8 & 654,813 & 22.4 & $4,863,276$ & 51.8 \\
\hline $45-64$ & 227,930 & 47.9 & 296,914 & 48.0 & $1,127,265$ & 38.6 & $2,981,705$ & 31.7 \\
\hline $65-84$ & 107,821 & 22.7 & 136,227 & 22.0 & 999,353 & 34.2 & $1,389,782$ & 14.8 \\
\hline $84+$ & 895 & 0.2 & 1163 & 0.2 & 139,559 & 4.8 & 162,823 & 1.7 \\
\hline Missing & - & 0.0 & - & 0.0 & - & 0.0 & - & 0.0 \\
\hline New OHIP registrants (within 10 years) No. (\%) & 13,742 & 2.9 & 29,981 & 4.9 & 157,488 & 5.4 & $1,200,951$ & 12.8 \\
\hline \multicolumn{9}{|l|}{ Income quintile, No. (\%) } \\
\hline 1 (low) & 84,198 & 17.7 & 101,739 & 16.5 & 583,685 & 20.0 & $1,799,279$ & 19.2 \\
\hline 2 & 96,387 & 20.3 & 115,903 & 18.7 & 605,293 & 20.7 & $1,884,459$ & 20.1 \\
\hline 3 & 95,925 & 20.2 & 125,618 & 20.3 & 588,141 & 20.1 & $1,892,274$ & 20.1 \\
\hline 4 & 96,214 & 20.2 & 132,243 & 21.4 & 570,140 & 19.5 & $1,903,560$ & 20.3 \\
\hline 5 (high) & 101,596 & 21.4 & 141,926 & 23.0 & 565,536 & 19.4 & $1,888,811$ & 20.1 \\
\hline Missing & 1291 & 0.3 & 934 & 0.2 & 8195 & 0.3 & 29,203 & 0.3 \\
\hline \multicolumn{9}{|l|}{ Rurality Index of Ontario, No. (\%) } \\
\hline Major urban (0 to 9) & 257,792 & 54.2 & 475,286 & 76.9 & $2,026,660$ & 69.4 & 6698,329 & 71.3 \\
\hline Semi-urban (10 to 39) & 150,810 & 31.7 & 111,986 & 18.1 & 608,960 & 20.9 & $1,852,225$ & 19.7 \\
\hline Rural $(\geq 40)$ & 63,866 & 13.4 & 28,970 & 4.7 & 260,936 & 8.9 & 761,861 & 8.1 \\
\hline Missing & 3143 & 0.7 & 2121 & 0.3 & 24,434 & 0.8 & 85,171 & 0.9 \\
\hline \multicolumn{9}{|l|}{ Resource utilization band (RUB), No. (\%) } \\
\hline 0 (non-user) & 2157 & 0.5 & 2431 & 0.4 & 30,338 & 1.0 & 938,240 & 10.0 \\
\hline 1 & 2252 & 0.5 & 2595 & 0.4 & 11,227 & 0.4 & 555,466 & 5.9 \\
\hline 2 & 23,325 & 4.9 & 27,403 & 4.4 & 114,781 & 3.9 & $1,588,712$ & 16.9 \\
\hline 3 & 306,213 & 64.4 & 399,620 & 64.6 & $1,691,226$ & 57.9 & $4,685,817$ & 49.9 \\
\hline 4 & 109,010 & 22.9 & 146,389 & 23.7 & 734,298 & 25.1 & $1,253,298$ & 13.3 \\
\hline 5 (very high user) & 32,654 & 6.9 & 39,925 & 6.5 & 339,120 & 11.6 & 376,053 & 4.0 \\
\hline \multicolumn{9}{|l|}{ Missing } \\
\hline \multicolumn{9}{|l|}{ Patients with Chronic disease } \\
\hline 2 + Co-morbidity No. (\%) & 475,611 & 100.0 & 618,363 & 100.0 & $2,920,990$ & 100.0 & $2,920,990$ & 31.1 \\
\hline 3+ comorbidities No. (\%) & 194,828 & 41.0 & 257,141 & 41.6 & $1,481,098$ & 50.7 & $1,481,098$ & 15.8 \\
\hline 4+ comorbidities No. (\%) & 71,285 & 15.0 & 95,323 & 15.4 & 723,296 & 24.8 & 723,296 & 7.7 \\
\hline 5+ comorbidities No. (\%) & 23,824 & 5.0 & 323,368 & 5.2 & 344,685 & 11.8 & 344,685 & 3.7 \\
\hline
\end{tabular}

(B2-B1) and $1.47 \%$ (p-value 0.2798$)$ among noninterprofessional teams (A2-A1). The differenceindifferences $(\mathrm{B} 2-\mathrm{B} 1)-(\mathrm{A} 2-\mathrm{A} 1)$ was non-significant at $3.43 \%$ ( $p$-value 0.0975$)$ (Table 8$)$.

\section{Discussion}

We used administrative databases to assess the association between receiving care from interprofessional and non-interprofessional primary care teams and unplanned 
Table 3 ACSC hospital admissions between April 1st, 2015 and February 28th, 2017 among multi-morbid adults by physician characteristics identified on March 31st, 2015

\begin{tabular}{|c|c|c|c|c|c|c|c|}
\hline & \multicolumn{3}{|c|}{ Interprofessional Teams } & \multicolumn{3}{|c|}{ Non-interprofessional teams } & \multirow[b]{2}{*}{$\begin{array}{l}\text { Rate Difference } \\
\text { (interprofessional } \\
\text { Teams - } \\
\text { Non-interprofessiona } \\
\text { teams) }\end{array}$} \\
\hline & Numerator & Denominator & Rate per 100 & Numerator & Denominator & Rate per 100 & \\
\hline ACSC admissions and patients totals & 11,963 & 475,611 & 2.5 & 13,160 & 618,363 & 2.1 & 0.4 \\
\hline \multicolumn{8}{|l|}{ Physicians characteristics } \\
\hline \multicolumn{8}{|l|}{ Sex } \\
\hline Male & 8183 & 298,763 & 2.7 & 9547 & 407,328 & 2.3 & 0.4 \\
\hline Female & 3780 & 176,848 & 2.1 & 3613 & 210,599 & 1.7 & 0.4 \\
\hline Missing & & & & & 436 & 0.0 & \\
\hline \multicolumn{8}{|l|}{ Age group } \\
\hline$<40$ & 2013 & 80,487 & 2.5 & 1098 & 54,012 & 2.0 & 0.5 \\
\hline $40-64$ & 8170 & 332,177 & 2.5 & 9242 & 445,990 & 2.1 & 0.4 \\
\hline$>64$ & 1648 & 58,240 & 2.8 & 2730 & 114,424 & 2.4 & 0.4 \\
\hline Missing & 132 & 4707 & 2.8 & 90 & 3937 & 2.3 & 0.5 \\
\hline \multicolumn{8}{|l|}{ Country of medical graduation Canada } \\
\hline Yes & 9389 & 379,843 & 2.5 & 9459 & 456,855 & 2.1 & 0.4 \\
\hline No & 2442 & 91,061 & 2.7 & 3611 & 157,571 & 2.3 & 0.4 \\
\hline Missing & 132 & 4707 & 2.8 & 90 & 3937 & 2.3 & 0.5 \\
\hline \multicolumn{8}{|l|}{ Years in practice } \\
\hline$<5$ & 246 & 9457 & 2.6 & 180 & 6971 & 2.6 & 0.0 \\
\hline 5_15 & 2650 & 105,104 & 2.5 & 1464 & 71,094 & 2.1 & 0.4 \\
\hline $16-25$ & 2571 & 107,080 & 2.4 & 3047 & 144,860 & 2.1 & 0.3 \\
\hline$>25$ & 6496 & 253,970 & 2.6 & 8460 & 395,002 & 2.1 & 0.5 \\
\hline Missing & & - & & 9 & 436 & 2.1 & -2.1 \\
\hline
\end{tabular}

ACSC hospitalizations and all cause hospital readmissions among multi-morbid patients. We followed the same patients before and after teams were implemented which allowed an assessment of the effect of the intervention-introduction of interprofessional team-based care. When we investigated the outcomes during the most recent available period of April 1st, 2015 to March 31st, 2017 interprofessional teams were found to have higher ACSC admission and hospital readmission rates as compared to non-interprofessional teams. However, when we compared the outcomes over time, interprofessional teams were not associated with either an increase or a reduction of ACSC hospital admission and hospital readmission.

The results are consistent with previous evidence that looked at utilization in relation to interprofessional team-based care and found differences in quality but not in healthcare utilization and cost [46-49]. One US study that evaluated the effect of multiplayer patient-centred medical home on healthcare utilization did not find a significant reduction in inpatient admissions [50]. In contrast, several studies from the US assessed multiple components of the medical home model on health services utilization and found significant lower rates of avoidable hospitalization when more medical homeness was incorporated in the health system [51-53]. Implementation of Family Health Teams appeared to contribute to a reduction in ACSC hospitalizations in a Brazilian metropolis, Belo Horizonte [54].

There is a body of evidence that links chronic disease management programs to lower preventable hospitalizations [55-58]. In Ontario, patients being served by both interprofessional and non-interprofessional teams have access to certain chronic disease programs including diabetes education and heart failure clinics. This could be one of the reasons for the absence of difference in our study between receiving care from interprofessional and non-interprofessional teams in ACSC hospitalizations. Additionally, there is heterogeneity of interprofessional teams features across Ontario. Interprofessional team's 
Table 4 ACSC hospital admissions between April 1st, 2015 and March31st, 2017 among multi-morbid adults by patient characteristics from March 31st, 2003

\begin{tabular}{|c|c|c|c|c|c|c|c|}
\hline \multirow[b]{3}{*}{ ACSC admissions and patients totals } & \multicolumn{7}{|c|}{ Patients characteristics } \\
\hline & \multirow{2}{*}{$\frac{\text { Numerator }}{11,963}$} & \multirow{2}{*}{$\begin{array}{l}\text { Denominator } \\
475,611\end{array}$} & \multicolumn{5}{|l|}{ Rate per 100} \\
\hline & & & 2.52 & 13,160 & 618,363 & 2.13 & 0.39 \\
\hline \multicolumn{8}{|l|}{ Sex } \\
\hline Males & 5265 & 186,729 & 2.8 & 5869 & 246,882 & 2.4 & 0.4 \\
\hline Female & 6698 & 288,882 & 2.3 & 7291 & 371,481 & 2.0 & 0.3 \\
\hline Missing & - & - & & - & - & 0.0 & \\
\hline
\end{tabular}

Age group, yr.

$18-44$
$45-64$
$65+$
Missing
New OHIP registrants (within 10 years)

Yes

No

Income quintile

1 (low)

2

3

4

5 (high)

Missing

\section{Rurality Index of Ontario}

Major urban (0 to 9)

Semi-urban (10 to 39)

Rural $(\geq 40)$

Missing

\section{Resource utilization band (RUB)}

0 (non-user)

1

2

3

4

5 (very high user)

Missing

Patients with Chronic disease

$$
\begin{aligned}
& 2+\text { Co-morbidity } \\
& \text { Yes } \\
& \text { No } \\
& 3+\text { comorbidities } \\
& \text { Yes } \\
& \text { No }
\end{aligned}
$$

4+ comorbidities

$$
\text { Yes }
$$

\section{8,965 \\ 227,930}

108,716

$-$

294

11,669

13,742

461,869

2742

2710

2338

2161

1972

40

84,198

96,387

95,925

96,214

101,596

1291

5741

4062

2060

100

257,792

150,810

63,866

3143

2157

2252

23,325

306,213

109,010

32,654

37

399

6410

3370

1707
0.9

2.3

5.1

2.1

2.5

3.3

2.8

2.4

2.2

1.9

3.1

11,963

475,611

2.5

257,141

280,783

4328

4213

71,285

3.2

1.7

$$
\text { - }
$$

7635

3.0

1.5

5.9
1288

5665

6207

184,059

296,914

137,390

$-$

470

12,690

29,981

588,382

2859

2815

2631

2545

2290

20

9396

2809

881

74

56

27

382

7081

3773

1841

618,363

2.1

0.4

8657

4503

257,141

361,222

3.4

$-0.4$

4841

95,323

5.1

0.8 
Table 4 ACSC hospital admissions between April 1st, 2015 and March31st, 2017 among multi-morbid adults by patient characteristics from March 31st, 2003 (Continued)

\begin{tabular}{|c|c|c|c|c|c|c|c|}
\hline \multirow[b]{3}{*}{ ACSC admissions and patients totals } & \multicolumn{7}{|c|}{ Patients characteristics } \\
\hline & \multirow{2}{*}{$\frac{\text { Numerator }}{11,963}$} & \multirow{2}{*}{$\begin{array}{l}\text { Denominator } \\
475,611\end{array}$} & \multicolumn{5}{|l|}{ Rate per 100} \\
\hline & & & 2.52 & 13,160 & 618,363 & 2.13 & 0.39 \\
\hline No & 7750 & 404,326 & 1.9 & 8319 & 523,040 & 1.6 & 0.3 \\
\hline \multicolumn{8}{|l|}{$5+$ comorbidities } \\
\hline Yes & 1949 & 23,824 & 8.2 & 2329 & 32,368 & 7.2 & 1 \\
\hline No & 10,014 & 451,787 & 2.2 & 10,831 & 585,995 & 1.8 & 0.4 \\
\hline
\end{tabular}

composition and the skills mix vary across the different teams. Some interprofessional teams are colocated others are not. Hence, some interprofessional teams might not be ideally set up for care coordination and continuity of care. Continuity of care might be reduced within interprofessional teams if they are not well coordinated and might present a potential for fragmented care. Available evidence from a systematic review suggests that having an accessible and a long-term relationship with a primary care provider appeared to be more important in reducing potentially avoidable hospitalizations than how the primary care delivery is organized. Long-term relationships between primary care physicians and patients reduces hospitalizations for chronic ACSCs and continuity of care has been associated with both reduced health services utilization and patient satisfaction [59-61]. Continuity of care is critical to ensuring that everyone with chronic medical needs receive effective, timely and safe health care [52].

Table 5 All cause hospital readmissions among multi-morbid adults between April 1 ${ }^{\text {st }}, 2015$ and March 31 st, 2017 by physician characteristics based March 31st, 2017

\begin{tabular}{|c|c|c|c|c|c|c|c|}
\hline & \multicolumn{3}{|c|}{ Interprofessional Teams } & \multicolumn{3}{|c|}{ Non-interprofessional teams } & \multirow[b]{2}{*}{$\begin{array}{l}\text { Rate Difference } \\
\text { (Interprofessional Teams - } \\
\text { Non-interprofessional teams }\end{array}$} \\
\hline & Numerator & Denominator & Rate per 100 & Numerator & Denominator & Rate per 100 & \\
\hline $\begin{array}{l}\text { All-cause readmissions } \\
\text { and patient totals }\end{array}$ & 1796 & 11,963 & 15.0 & 1917 & 13,160 & 14.6 & 0.4 \\
\hline \multicolumn{8}{|l|}{ Sex No. (\%) } \\
\hline Male & 1231 & 8183 & 15.0 & 1375 & 9547.00 & 14.4 & 0.6 \\
\hline Female & 565 & 3780 & 14.9 & 542 & 3613.00 & 15.0 & -0.1 \\
\hline Missing & 0 & 0 & 0.0 & 0 & 0.00 & 0.0 & 0 \\
\hline \multicolumn{8}{|l|}{ Age group No. (\%) in Yrs. } \\
\hline$<40$ & 320 & 2013 & 15.9 & 156 & 1098.00 & 14.2 & 1.7 \\
\hline $40-64$ & 1208 & 8170 & 14.8 & 1346 & 9242.00 & 14.6 & 0.2 \\
\hline $65+$ & 255 & 1648 & 15.5 & 404 & 2730.00 & 14.8 & 0.7 \\
\hline Missing & 13 & 132 & 9.8 & 11 & 90.00 & 12.2 & -2.4 \\
\hline \multicolumn{8}{|c|}{ Country of medical graduation Canada No. (\%) } \\
\hline Yes & 1405 & 9389 & 15.0 & 1369 & 9459.00 & 14.5 & 0.5 \\
\hline No & 378 & 2442 & 15.5 & 537 & 3611.00 & 14.9 & 0.6 \\
\hline Missing & 13 & 132 & 9.8 & 11 & 90.00 & 12.2 & -2.4 \\
\hline \multicolumn{8}{|l|}{ Years in practice No. (\%) } \\
\hline$<5$ & 36 & 246 & 14.6 & 24 & 189.00 & 12.7 & 1.9 \\
\hline 5_15 & 406 & 2650 & 15.3 & 204 & 1464.00 & 13.9 & 1.4 \\
\hline $16-25$ & 385 & 2571 & 15.0 & 437 & 3047.00 & 14.3 & 0.7 \\
\hline$>25$ & 969 & 6496 & 14.9 & 1252 & 8460.00 & 14.8 & 0.1 \\
\hline Missing & 0 & 0 & 0.0 & 0 & 0.00 & 0.00 & 0 \\
\hline
\end{tabular}


Table 6 All cause hospital readmissions between April 1st, 2015 and March31st, 2017 among multi-morbid adults by patient characteristics from March 31st, 2003

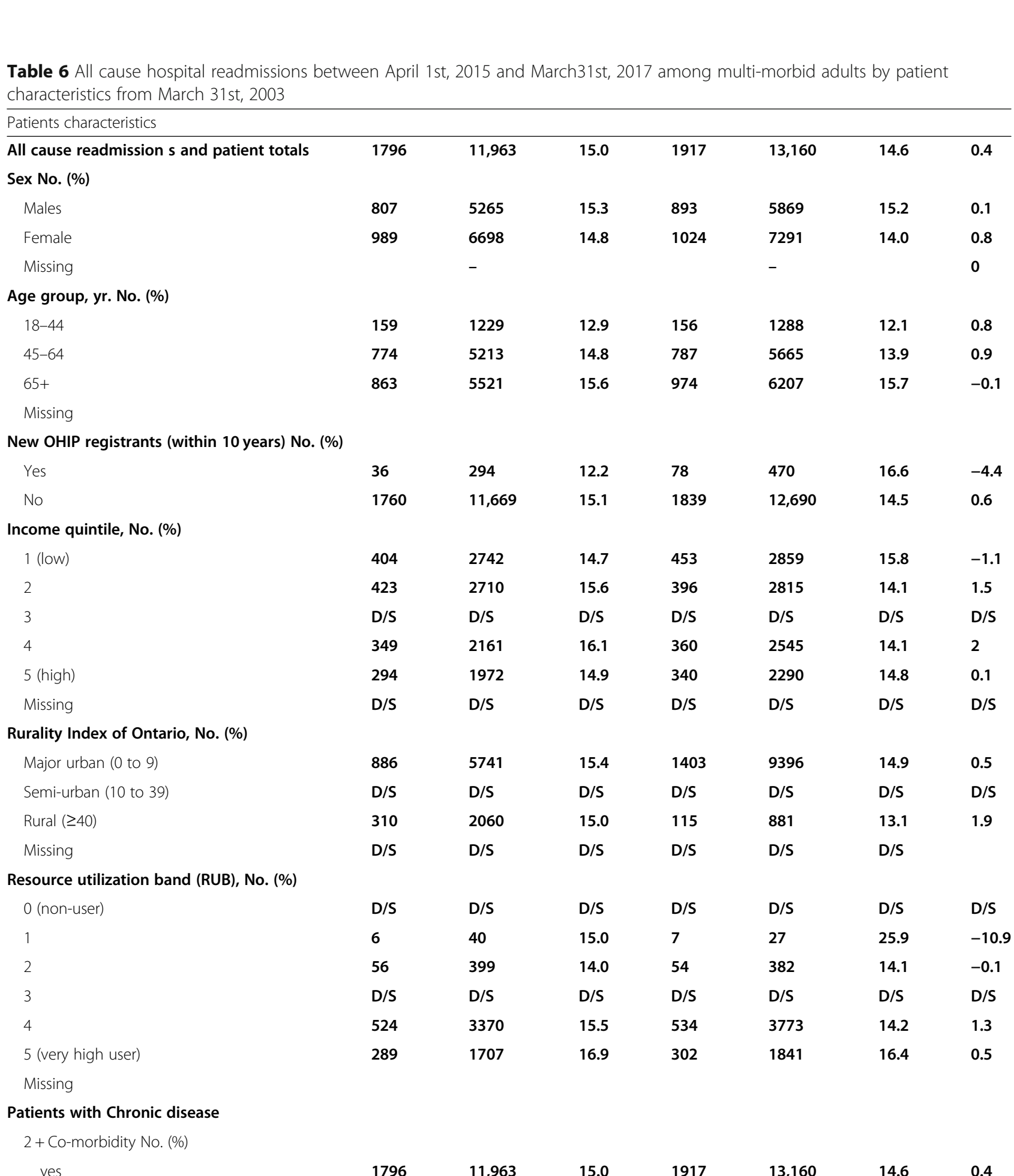

\section{Missing}

Patients with Chronic disease

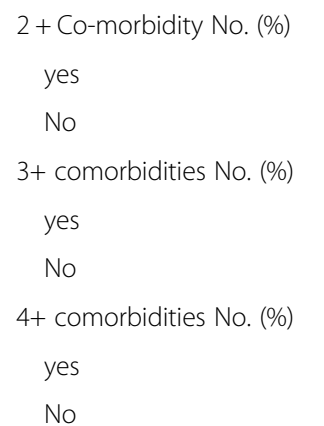

1796

11,963

15.0

1917

13,160

14.6

0.4

0

0

0

0

1226

7635

16.1

1335

8657

15.4

0.7

$570 \quad 4328$

13.2

582

4503

12.9

0.3

$697 \quad 4213$

$\begin{array}{ll}16.5 & 770 \\ 14.2 & 1147\end{array}$

4841

15.9

0.6

1099

7750

8319

13.8

0.4 
Table 6 All cause hospital readmissions between April 1st, 2015 and March31st, 2017 among multi-morbid adults by patient characteristics from March 31st, 2003 (Continued)

\begin{tabular}{|c|c|c|c|c|c|c|c|}
\hline Patients & & & & & & & \\
\hline $5+$ con & & & & & & & \\
\hline yes & 344 & 1949 & 17.7 & 378 & 2329 & 16.2 & 1.5 \\
\hline No & 1452 & 10,014 & 14.5 & 1539 & 10,831 & 14.2 & 0.3 \\
\hline
\end{tabular}

D/S refers to data supressed for observations with a count between 1 and 5 and have been suppressed to comply with Personal Health Information Protection Act privacy legislation

Based on Startfield's model a strong primary care system should be the first contact for care, as well as continuous, comprehensive and well-coordinated to reduce unwanted outcomes such as preventable hospitalizations [62]. It is important for any jurisdiction that has embarked on or is planning to set up primary care interprofessional team-based care to nurture all these enablers for a strong primary care system.

Our study has several limitations that should be acknowledged. First, administrative databases have not been originally set up for research purposes, which presented a potential for measurement error. However, all the databases used in our study have been validated in Ontario's context. Additionally, any potential measurement error will be non-deferential between interprofessional and non-interprofessional teams and should not bias the results in a meaningful way. Second, this is an observational study and is susceptible to unmeasured confounding. However, by comparing the outcomes over time, potential risk of bias from unmeasured confounders was limited.
Third, due to the adopted study design, to be included in the study population, patients had to survive throughout the study period-April 1st, 2003 to March 31st, 2017. However, a potential survival bias would have affected both interprofessional and noninterprofessional teams' patients equally and does not present a threat to internal validity. Fourth, ACSC medical admissions and all-cause readmissions are not all unnecessary and preventable. In contrast, in some cases, admission and readmission could be appropriate and reflect appropriate care in the community that flagged the need to be hospitalised.

\section{Conclusion}

Our study findings indicate that the introduction of interprofessional team-based primary care was not associated with reduction in avoidable hospitalizations and hospital readmissions. Those results were not in-line with our hypothesis as we expected that, over time, interprofessional teams would reduce the likelihood of ACSC admissions and readmissions. For jurisdictions aiming to expand physician participation in teams, our

Table 7 Association between enrolment in an interprofessional team-based model and ACSC admissions and all cause hospital readmissions post intervention April 1 ${ }^{\text {st }}, 2015$ to March 31st, 2017

\begin{tabular}{|c|c|c|c|c|}
\hline \multirow[b]{3}{*}{ Unadjusted (null model) } & \multicolumn{4}{|c|}{ Interprofessional team ACSC Admissions (Reference: Non-Interprofessional teams) } \\
\hline & OR & $95 \% \mathrm{Cl}$ & & $P$-Value \\
\hline & 1.19 & 1.16 & 1.22 & $<.0001$ \\
\hline \multicolumn{5}{|l|}{ Adjusted $^{a}$ for: } \\
\hline Physician group characteristics & 1.15 & 1.12 & 1.18 & $<.0001$ \\
\hline Group and physician characteristics & 1.17 & 1.13 & 1.18 & $<.0001$ \\
\hline \multirow[t]{3}{*}{ Group, physician and patients } & 1.07 & 1.04 & 1.18 & $<.0001$ \\
\hline & \multicolumn{4}{|c|}{ Interprofessional team readmission s (Reference: non-teams) } \\
\hline & OR & $95 \% \mathrm{Cl}$ & & $P$-Value \\
\hline Unadjusted (null model) & 1.31 & 0.98 & 1.75 & 0.073 \\
\hline \multicolumn{5}{|l|}{ Adjusted $^{a}$ for: } \\
\hline Physician group characteristics & 1.17 & 0.86 & 1.60 & 0.323 \\
\hline Group and physician characteristics & 1.17 & 0.84 & 1.60 & 0.323 \\
\hline Group, physician and patients & 1.20 & 0.84 & 1.65 & 0.260 \\
\hline
\end{tabular}

${ }^{a}$ Adjustment used physician groups and physicians' characteristics from March 31st, 2015 (post-intervention) and patients' characteristics from March 31st, 2003 (pre-intervention) 


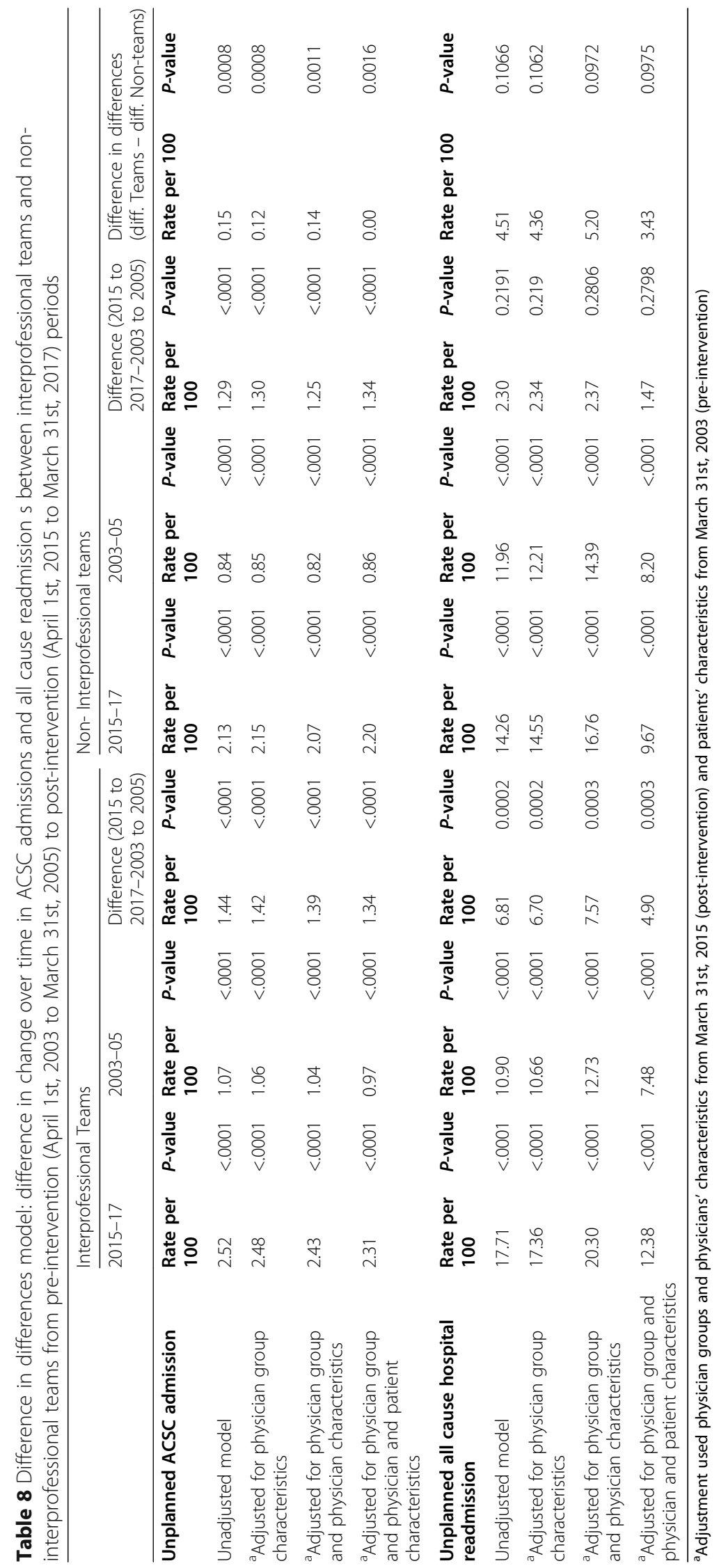


study results point to the need to couple interprofessional team-based care with other enablers of a strong primary care system such as access, continuity, comprehensiveness and coordination. Policies and practices that enhance those features will help to implement interprofessional team-based care in a way that it is best able to deliver on intended outcomes such as improving health services utilization efficiency.

\section{Appendix 1}

\section{List of diagnostic information for defining the 17 selected chronic conditions under investigation in this study}

Table 9 These conditions represent a subset of all possible chronic conditions that may be experienced by individuals over a lifetime but represent the most substantial conditions from a population perspective.

\begin{tabular}{|c|c|c|c|}
\hline Condition [reference for validated algorithm] & ICD 9 / OHIP & ICD 10 & $\mathrm{ODB}^{a}$ \\
\hline Acute Myocardial Infarction (AMI) [1] & 410 & 121,122 & \\
\hline \multicolumn{4}{|l|}{ Osteo- and other Arthritis: } \\
\hline (A) Osteoarthritis & 715 & M15-M19 & \\
\hline $\begin{array}{l}\text { (B) Other Arthritis (includes Synovitis, Fibrositis, } \\
\text { Connective tissue disorders, Ankylosing } \\
\text { spondylitis, Gout Traumatic arthritis, pyogenic } \\
\text { arthritis, Joint derangement, Dupuytren's } \\
\text { contracture, Other MSK disorders) }\end{array}$ & $\begin{array}{l}727,729,710,720,274,716 \\
711,718,728,739\end{array}$ & $\begin{array}{l}\text { M00-M03, M07, M10, M11-M14, M20- } \\
\text { M25, M30-M36, M65-M79 }\end{array}$ & \\
\hline Arthritis - Rheumatoid arthritis [2] & 714 & M05-M06 & \\
\hline Asthma [3] & 493 & $\mathrm{~J} 45$ & \\
\hline (all) Cancers & $140-239$ & C00-C26, C30-C44, C45-C97 & \\
\hline Cardiac Arrhythmia & $427(\mathrm{OHIP}) / 427.3(\mathrm{DAD})$ & $148.0,148.1$ & \\
\hline Congestive Heart Failure [4] & 428 & 1500, 1501, 1509 & \\
\hline Chronic Obstructive Pulmonary Disease [5] & $491,492,496$ & $J 41, J 43, J 44$ & \\
\hline Coronary syndrome (excluding AMI) & $411-414$ & $120,122-125$ & \\
\hline Dementia [6] & $\begin{array}{l}\text { 290, } 331(\mathrm{OHIP}) / \text { 046.1, 290.0, } \\
\text { 290.1, 290.2, 290.3, 290.4, 294, } \\
331.0,331.1,331.5, \mathrm{~F} 331.82 \\
(\mathrm{DAD})\end{array}$ & F00, F01, F02, F03, G30 & $\begin{array}{l}\text { Cholinesterase } \\
\text { Inhibitors }\end{array}$ \\
\hline Diabetes [7] & 250 & E08- E13 & \\
\hline Hypertension [8] & $401,402,403,404,405$ & $|10| 11,,|12| 13,, \mid 15$ & \\
\hline Inflomatary Bowel Disease (IBD) [9] & 555,556 & $\mathrm{~K} 50, \mathrm{k} 51$ & \\
\hline (Other) Mental IIInesses & $\begin{array}{l}291,292,295,297,298,299 \\
301,302,303,304,305,306 \\
307,313,314,315,319\end{array}$ & $\begin{array}{l}\text { F04, F050, F058, F059, F060, F061, F062, F063, } \\
\text { F064, F07, F08, F10, F11, F12, F13, F14, F15, F16, } \\
\text { F17, F18, F19, F20, F21, F22, F23, F24, F25, F26, } \\
\text { F27, F28, F29, F340, F35, F36, F37, F430, F439, } \\
\text { F453, F454, F458, F46, F47, F49, F50, F51, F52, } \\
\text { F531, F538, F539, F54, F55, F56, F57, F58, F59, } \\
\text { F60, F61, F62, F63, F64, F65, F66, F67, F681, F688, } \\
\text { F69, F70, F71, F72, F73, F74, F75, F76, F77, F78, } \\
\text { F79, F80, F81, F82, F83, F84, F85, F86, F87, F88, } \\
\text { F89, F90, F91, F92, F931, F932, F933, F938, F939, } \\
\text { F94, F95, F96, F97, F98 }\end{array}$ & \\
\hline $\begin{array}{l}\text { Mood, anxiety, depression and other } \\
\text { nonpsychotic disorders }\end{array}$ & 296, 300, 309, 311 & $\begin{array}{l}\text { F30, F31, F32, F33, F34 (excl. F34.0), F38, F39, F40, } \\
\text { F41, F42, F43.1, F43.2, F43.8, F44, F45.0, F45.1, } \\
\text { F45.2, F48, F53.0, F68.0, F93.0, F99 }\end{array}$ & \\
\hline Osteoporosis & 733 & M81, M82 & \\
\hline Renal failure & $403,404,584,585,586, v 451$ & N17, N18, N19, T82.4, Z49.2, Z99.2 & \\
\hline Stroke (excluding transient ischemic attack) & $430,431,432,434,436$ & $160-164$ & \\
\hline
\end{tabular}

Abbreviations: ICD International Classification of Disease, ODB Ontario Drug Benefit program database, OHIP Ontario Health Insurance Plan, physician billings database

All case definitions look back to 2001 to ascertain disease status, with the exception of AMI (1 year prior to index), Cancer ( 2 years), Mood Disorder ( 2 years) and Other Mental IIInesses (2 years)

AMI, Asthma, COPD, CHF, Dementia, Diabetes Hypertension and Rheumatoid Arthritis are based on validated case algorithms (see Sources 1-8 below, respectively). All other conditions required at least one diagnosis recorded in acute care (CIHI) or two diagnoses recorded in physician billings within a two-year period

${ }^{\mathrm{a} O D B}$ prescription drug records are not available for the majority of persons under the age of 65 


\section{Appendix 2}

Table $\mathbf{1 0}$ List of Eligible CMGs for hospital readmission

List of Eligible Conditions (CMGs)

CMG+

Stroke (Age $\geq 45)$

CMG 2008

25

26

28

CMG 2009

25

26

28

COPD (Age $\geq 45$ )

CMG 2008

139

CMG 2009

Pneumonia (All ages)

CMG 2008

CMG 2009

Congestive Heart Failure (Age $\geq 45$ )

CMG 2008

CMG 2009

Diabetes (All ages)

CMG 2008

CMG 2009

Cardiac CMGs (Age $\geq 40$ )

CMG 2008

CMG 2009

\section{Gastrointestinal CMGs (All ages)}

CMG 2008

CMG+ description

Hemorrhagic Event of Central Nervous System Ischemic Event of Central Nervous System Unspecified Stroke

Hemorrhagic Event of Central Nervous System Ischemic Event of Central Nervous System Unspecified Stroke

Chronic Obstructive Pulmonary Disease

Chronic Obstructive Pulmonary Disease

Bacterial Pneumonia

Viral/Unspecified Pneumonia

Disease of Pleura

Bacterial Pneumonia

Viral/Unspecified Pneumonia

Disease of Pleura

Heart Failure without Cardiac Catheter

Heart Failure without Cardiac Catheter

Diabetes

Diabetes

Arrhythmia without Cardiac Catheter

Unstable Angina/Atherosclerotic Heart Disease without Cardiac Cath

Angina (except Unstable)/Chest Pain without Cardiac Catheter

Arrhythmia without Cardiac Catheter

Unstable Angina/Atherosclerotic Heart Disease without Cardiac Cath

Angina (except Unstable)/Chest Pain without Cardiac Catheter

Minor Upper Gastrointestinal Intervention

Severe Enteritis

Complicated Ulcer

Inflammatory Bowel Disease

Gastrointestinal Hemorrhage

C

Esophagitis/Gastritis/Miscellaneous Digestive Disease Symptom/Sign of Digestive System 


\section{Abbreviations}

ACSCs: Ambulatory care sensitive conditions; US: United States; FHO: Family Health Organization; COPD: Chronic obstructive pulmonary disease; CMG: Case Mix Group; DAD: Discharge Abstract Database; Registered Patient Database: RPDB; RIO: Rurality Index of Ontario; RUBs: Resource Utilization Bands; OHIP: Ontario Health Insurance Plan

\section{Acknowledgements}

Not applicable.

\section{Authors' contributions}

WHA: Conceptualization, Methodology, Formal Analysis, Writing-Original Draft. RM: Conceptualization, Methodology, Formal Analysis, Writing-Review \& Editing.BH: Conceptualization, Methodology, Writing-Review \& Editing, Supervision. WPW: Conceptualization, Methodology, Writing-Review \& Editing, Supervision. RHG: Conceptualization, Methodology, Writing-Review \& Editing, Supervision. All authors have read and approved the manuscript.

\section{Funding}

This study was supported by ICES, which is funded by an annual grant from the Ontario Ministry of Health and Long-Term Care (MOHLTC). ICES is an independent, non-profit research institute funded by an annual grant from the Ontario Ministry of Health and Long-Term Care (MOHLTC). As a prescribed entity under Ontario's privacy legislation, ICES is authorized to collect and use health care data for the purposes of health system analysis, evaluation and decision support. Secure access to these data is governed by policies and procedures that are approved by the Information and Privacy Commissioner of Ontario. Parts of this material are based on data and information compiled and provided by the Canadian Institute for Health Information $(\mathrm{CIHI})$. The analyses, conclusions, opinions and statements expressed herein are solely those of the authors and do not reflect those of the funding or data sources; no endorsement is intended or should be inferred. Richard $\mathrm{H}$. Glazier is supported as a Clinician Scientist in the Department of Family and Community Medicine at St. Michael's Hospital and at the University of Toronto.

\section{Availability of data and materials}

The dataset from this study is held securely in coded form at ICES. While data sharing agreements prohibit ICES from making the dataset publicly available, access may be granted to those who meet pre-specified criteria for confidential access, available at www.ices.on.ca/DAS. The full dataset creation plan and underlying analytic code are available from the authors upon request, understanding that the computer programs may rely upon coding templates or macros that are unique to ICES and are therefore either inaccessible or may require modification.

\section{Ethics approval and consent to participate}

ICES (formerly known as Institute for Clinical Evaluative Sciences) is a prescribed entity under section 45 of Ontario's Personal Health Information Protection Act. Section 45 authorizes ICES to collect personal health information, without consent, for the purpose of analysis or compiling statistical information with respect to the management of, evaluation or monitoring of, the allocation of resources to or planning for all or part of the health system. Projects conducted under section 45, by definition, do not require review by a Research Ethics Board. This project was conducted under section 45, and approved by ICES' Privacy and Legal Office.

\section{Consent for publication}

Not applicable.

\section{Competing interests}

The authors declare that they have no competing interests.

\section{Author details}

${ }^{1}$ Dalla Lana School of Public Health, Toronto, Ontario, Canada. ${ }^{2}$ Institute of Health Policy, Management and Evaluation, University of Toronto, 155 College Street, Toronto, Ontario M5T 3M6, Canada. ${ }^{3}$ Canadian Centre for Health Economics, Toronto, Canada. ${ }^{4}$ Institute for Clinical Evaluative Sciences, Toronto, Canada. ${ }^{5}$ Department of Family and Community Medicine, University of Toronto, Toronto, Ontario, Canada. ${ }^{6}$ Departments of Family
Medicine and Health Research Methods, Evidence and Impact, McMaster University, Hamilton, Canada. ${ }^{7}$ Trillium Health Partners, Institute for Better Health, Toronto, Ontario, Canada. ${ }^{8}$ MAP Centre for Urban Health Solutions, St. Michael's Hospital, Toronto, Canada.

\section{Received: 10 May 2020 Accepted: 14 August 2020}

Published online: 24 August 2020

\section{References}

1. Chisholm D, Evans DB. Improving health system efficiency as a means of moving towards universal coverage. World Health Report (2010), Background Paper, 28. 2010. Available: http://www.who.int/healthsystems/ topics/financing/healthreport/28UCefficiency.pdf. Accessed 2 Feb 2016.

2. Berwick DM, Nolan TW, Whittington J. The triple aim: care, health, and cost. Health Aff (Millwood). 2008;27(3):759-69. https://doi.org/10.1377/ hlthaff.27.3.759.

3. Jencks SF, Williams MV, Coleman EA. Rehospitalizations among patients in the Medicare fee-for-service program. N Engl J Med. 2009;360(14):1418-28.

4. Soeken $\mathrm{KL}$, et al. Predictors of hospital readmission: a meta-analysis. Eval Health Prof. 1991;14(3):262-81.

5. Frankl SE, Breeling JL, Goldman L. Preventability of emergent hospital readmission. Am J Med. 1991;90(6):667-74.

6. Anderson GF, Steinberg EP. Hospital readmissions in the Medicare population. N Engl J Med. 1984;311(21):1349-53.

7. Billings J, Zeitel L, Lukomnik J, Carey TS, Blank AE, Newman L. Impact of socioeconomic status on hospital use in New York City. Health Aff (Millwood). 1993;12(1):162-73.

8. Brown RS, Peikes D, Peterson G, Schore J, Razafindrakoto CM. Six features of Medicare coordinated care demonstration programs that cut hospital admissions of HighRisk patients. Health Aff. 2012;31(6):1156-66.

9. Canadian Institute for Health Information. Seniors and the health care system: what is the impact of multiple chronic conditions. Toronto: Canadian Institute for Health Information; 2011.

10. Freund T, Kunz CU, Ose D, Peters-Klimm F. Patterns of multimorbidity in primary care patients at high risk of future hospitalization. Popul Health Manag. 2012;15:119-24.

11. Marengoni A, Fratiglioni L. Disease clusters in older adults: rationale and need for investigation. J Am Geriatr Soc. 2011;59:2395-6.

12. Lochner KA, Goodman RA, Posner S, Parekh A. Multiple chronic conditions among Medicare beneficiaries: state-level variations in prevalence, utilization, and cost, 2011. Medicare Medicaid Res Rev. 2013;3(3):mmrr.003. 03.b02. https://doi.org/10.5600/mmrr.003.03.b02.

13. Boult $C$, et al. Screening elders for risk of hospital admission. J Am Geriatr Soc. 1993;41(8):811-7.

14. van Walraven C, et al. Derivation and validation of an index to predict early death or unplanned readmission after discharge from hospital to the community. CMAJ. 2010;182(6):551-7.

15. Krumholz HM, et al. Readmission after hospitalization for congestive heart failure among Medicare beneficiaries. Arch Intern Med. 1997;157(1):99-104

16. Weissman JS, Stern RS, Epstein AM. The impact of patient socioeconomic status and other social factors on readmission: a prospective study in four Massachusetts hospitals. Inquiry. 1994;31(2):163-72.

17. Hutchison B, LEVESQUE JF, Strumpf E, Coyle N. Primary health care in Canada: systems in motion. Milbank Q. 2011;89(2):256-88.

18. Commission on the Future of Health Care in Canada. Building on values: the future of health care in Canada — final report. Saskatoon: Government of Canada; 2002. Available from: http://publications.gc.ca/collections/ Collection/CP32-85-2002E.pdf.

19. Standing Senate Committee on Social Affairs, Science, and Technology. The health of Canadians — federal role-final report. Vol. 6, Recommendations for reform. Ottawa: Parliament of Canada. Available from: http://www.parl. gc.ca/Content/SEN/Committee/372/soci/rep/repoct02vol6-e.htm.

20. Patients Medical Home available at: https://patientsmedicalhome.ca/. Accessed 31 Dec 2019

21. Hutchison B, Glazier R. Ontario's primary care reforms have transformed the local care landscape, but a plan is needed for ongoing improvement. Health Aff. 2013;32(4):695-703. https://doi.org/10.1377/hlthaff.2012.1087.

22. Coyle N, Strumpf E, Fiset-Laniel J, Tousignant P, Roy Y. Characteristics of physicians and patients who join team-based primary care practices: evidence from Quebec's family medicine groups. Health Policy. 2014;116(23):264-72. https://doi.org/10.1016/j.healthpol.2014.02.010. 
23. American Academy of Family Physicians. American college of physicians, American osteopathic association. Joint principles of the patient-centered medical home. 2007. Available at: https://www.aafp.org/dam/AAFP/ documents/practice_management/pcmh/initiatives/PCMHJoint.pdf.

24. Rosenthal TC. The medical home: growing evidence to support a new approach to primary care. J Am Board Fam Med. 2008;21(5):427-40. https:// doi.org/10.3122/jabfm.2008.05.070287.

25. Excellent Care for All. Available from: http://www.health.gov.on.ca/en/pro/ programs/ecfa/action/acute/hsp_thc.aspx. Accessed Dec 2019.

26. Ontario Ministry of Finance. Ontario Fact Sheet April 2016 Available from: https://www.fin.gov.on.ca/en/economy/ecupdates/factsheet.html Accessed 31 Dec 2019.

27. Kiran T, Kopp A, Glazier RH. Those left behind from voluntary medical home reforms in Ontario, Canada. Ann Family Med. 2016;14(6):517-25.

28. Dimick JB, Ryan AM. Methods for evaluating changes in health care policy. JAMA. 2014;312(22):2401-2.

29. Health Canada. Economic Burden of Illness in Canada, 1998. Ottawa: Public Health Agency of Canada; 2002. Available from: http://publications.gc.ca/ collections/Collection/H21-136-1998E.pdf. Accessed 19 June 2016.

30. Hanna A. Ontario medical association policy on chronic disease management. Toronto: OMA; 2009.

31. Statistics Canada. Tables by subject: Diseases and health conditions. http:// www.statcan.gc.ca/tables-tableaux/sum-som/101/ind01/13_2966_1887-eng. htm?hili_health03. Accessed 19 June 2016.

32. Canadian Institute for Health Information. Seniors and the health care system: what is the impact of multiple chronic conditions? Toronto: $\mathrm{CIHI} ; 2011$.

33. World Health Organization. Global status report on non-communicable diseases. Geneva: WHO; 2010

34. The Chief Public Health Officer. Annual report on the state of public health in Canada, 2010. Ottawa: Public Health Agency of Canada; 2010.

35. Pefoyo AJK, Bronskill SE, Gruneir A, Calzavara A, Thavorn K, Petrosyan Y, et al. The increasing burden and complexity of multimorbidity. BMC Public Health. 2015;15(1):1.

36. Gruneir A, Bronskill SE, Maxwell CJ, Bai YQ, Kone AJ, Thavorn K, et al. The association between multimorbidity and hospitalization is modified by individual demographics and physician continuity of care: a retrospective cohort study. BMC Health Serv Res. 2016;16(1):1.

37. Goodman RA, Posner SF, Huang ES, Parekh AK, Koh HK. Defining and measuring chronic conditions: imperatives for research, policy, program, and practice. Prev Chronic Dis. 2013;10:120239. https://doi.org/10.5888/ pcd10.120239.

38. Kralj B. Measuring Rurality -RIO2008 BASIC: methodology and results. Toronto: Ontario Medical Association; 2008.

39. The Johns Hopkins University. The Johns Hopkins ACG System. http://acg. jhsph.org/index.php. Accessed 25 March 2015.

40. Austin PC, Daly PA, Tu JV. A multicenter study of the coding accuracy of hospital discharge administrative data for patients admitted to cardiac care units in Ontario. Am Heart J. 2002;144(2):290-6. https://doi.org/10.1067/mhj. 2002.123839.

41. Gershon AS, Wang C, Guan J, Vasilevska-Ristovska J, Cicutto L, To T. Identifying patients with physician-diagnosed asthma in health administrative databases. Can Respir J. 2009:16(6):183-8.

42. Schultz SE, Rothwell DM, Chen Z. Tu K. identifying cases of congestive heart failure from administrative data: a validation study using primary care patient records. Chronic Dis Inj Can. 2013;33(3):160-6.

43. Hux JE, Ivis F, Flintoft V, Bica A. Diabetes in Ontario: determination ofprevalence and incidence using a validated administrative data algorithm. Diabetes Care. 2002;25(3):512-6.

44. Guttmann A, Nakhla M, Henderson M, To T, Daneman D, Cauch-Dudek K, et al. Validation of a health administrative data algorithm for assessing the epidemiology of diabetes in Canadian children. Pediatr Diabetes. 2010;11(2): 122-8. https://doi.org/10.1111/j.1399-5448.2009.00539.x.

45. Tu K, Campbell NR, Chen ZL, Cauch-Dudek KJ, McAlister FA. Accuracy of administrative databases in identifying patients with hypertension. Open Med. 2007;1(1):e18-26.

46. Kiran T, Kopp A, Moineddin R, Glazier RH. Longitudinal evaluation of physician payment reform and team-based care for chronic disease management and prevention. CMAJ. 2015 Nov 17;187(17):E494-502. https:// doi.org/10.1503/cmaj.150579.
47. Strumpf E, Ammi M, Diop M, Fiset-Laniel J, Tousignant P. The impact of team-based primary care on health care services utilization and costs: Quebec's family medicine groups. J Health Econ. 2017;55:76-94. https://doi. org/10.1016/j.jhealeco.2017.06.009.

48. Glazier RH, Hutchison B, Kopp A. Comparison of family health teams to other Ontario primary care models, 2004/05 to 2011/12. Toronto: Institute for Clinical Evaluative Sciences; 2015.

49. Glazier RH, Zagorski BM, Rayner J. Comparison of primary care models in Ontario by demographics, case mix and emergency department use, 2008/ 09 to 2009/10. ICES investigative report. Toronto: Institute for Clinical Evaluative Sciences; 2012

50. Rosenthal MB, Friedberg MW, Singer SJ, Eastman D, Li Z, Schneider EC. Effect of a multipayer patient-centered medical home on health care utilization and quality: the Rhode Island chronic care sustainability initiative pilot program. JAMA Intern Med. 2013;173:1907-13.

51. Cooley WC, MCAllister JW, Sherrieb K, Kuhlthau K. Improved outcomes associated with medical home implementation in pediatric primarybcare. Pediatrics. 2009;124:358-64

52. Fishman PA, Johnson EA, Coleman $\mathrm{K}$, et al. Impact on seniors of the patientcentered medical home: evidence from a pilot study. Gerontologist. 2012; 52:703-11.

53. Yoon J, Rose DE, Canelo I, et al. Medical home features of VHA primary care clinics and avoidable hospitalizations. J Gen Intern Med. 2013;28:1188-94.

54. Mendonça CS, et al. Trends in hospitalizations for primary care sensitive conditions following the implementation of family health teams in Belo Horizonte, Brazil. Health Policy Plan. 2011;27(4):348-55.

55. Cohen R, Lemieux J, Schoenborn J, Mulligan T. Medicare advantage chronic special needs plan boosted primary care, reduced hospital use among diabetes patients. Health Aff (Millwood). 2012;31:110-9.

56. Greisinger AJ, Balkrishnan R, Shenolikar RA, Wehmanen OA, Muhammad S, Champion PK. Diabetes care management participation in a primary care setting and subsequent hospitalization risk. Dis Manag. 2004;7:325-32.

57. Patel PH, Welsh C, Foggs MB. Improved asthma outcomes using a coordinated care approach in a large medical group. Dis Manag. 2004; 7:102-11.

58. Rea H, McAuley S, Stewart A, Lamont C, Roseman P, Didsbury P. A chronic disease management programme can reduce days in hospital for patients with chronic obstructive pulmonary disease. Intern Med J. 2004;34:608-14.

59. van Loenen T, van den Berg MJ, Westert GP, Faber MJ. Organizational aspects of primary care related to avoidable hospitalization: a systematic review. Fam Pract. 2014;31(5):502-16.

60. Cabana MD, Jee $\mathrm{SH}$. Does continuity of care improve patient outcomes? J Fam Pract. 2004;53:974-80.

61. Kringos DS, Boerma WG, Hutchinson a v d z J, Groenewegen PP. the breadth of primary care: a systematic literature review of its core dimensions. BMC Health Serv Res. 2010;10:65.

62. Starfield B. Is primary care essential? Lancet. 1994;344:1129-33.

\section{Publisher's Note}

Springer Nature remains neutral with regard to jurisdictional claims in published maps and institutional affiliations.

Ready to submit your research? Choose BMC and benefit from

- fast, convenient online submission

- thorough peer review by experienced researchers in your field

- rapid publication on acceptance

- support for research data, including large and complex data types

- gold Open Access which fosters wider collaboration and increased citations

- maximum visibility for your research: over $100 \mathrm{M}$ website views per year

At $\mathrm{BMC}$, research is always in progress.

Learn more biomedcentral.com/submission 